\title{
Validation of the Modes of Transmission of Mungbean Yellow Mosaic Virus (MYMV) in Mungbean [Vigna radiata (L.) Wilczek]
}

\author{
M. Mantesh*, Venkatesh and N.S. Pankaja \\ Department of Plant Pathology, College of Agriculture, V.C. Farm Mandya-571405, \\ University of Agricultural Sciences, Bengaluru-560 065, Karnataka, India \\ *Corresponding author
}

\begin{tabular}{|l|}
\hline Ke y w o r d s \\
Yellowing, \\
Puckering, Stunting, \\
Inoculation, Sap, \\
Aphids, Mungbean
\end{tabular}

\section{Introduction}

Mungbean [Vigna radiata $(\mathrm{L}$.$) Wilczek] is one$ of the important pulse crops in India. The crop is commonly called as greengram, mash, oreganpea, goldengram. In india, the name greengram is more commonly used than mungbean (Chatterjee and Randhawa, 1952).In India, Mungbean yellow mosaic is the most viral destructive disease of legumes popularly known as yellow plague of Kharif pulses. The typical symptoms of the yellow mosaic disease (YMD) in pulse crops are the small yellow spots on the leaf lamina in the initial stages. These yellow spots enlarge and give a mosaic appearance to the leaf and the spots later coalesce and result in the complete yellowing of the leaves. 
The yellow mosaic disease (YMD) of mungbean was first observed in 1955 at the experimental farm of the Indian Agricultural Research Institute, New Delhi. This disease was first reported by Nariani (1960) and it was named by Nene (1968) as Mungbean Yellow Mosaic Virus (MYMV). It is a geminivirus belongs to Family Geminiviridae, Subgroup II, Genus: Begomovirus containing ssDNA (Nariani, 1960). Studies on the distribution of begomoviruses inside the plants have clearly revealed that the begomoviruses are confined to phloem parenchyma and cambium, and other mesophyll parenchymatous tissue (Rojas et al., 2005). There are some reports suggesting sap transmission of virus in mungbean but not through the seed or any species of aphids. Geminiviruses are also transmitted through the seeds, among Geminiviridae, in the genus Curtovirus, is commonly transmitted through the seeds (Hull 2002). Bennett (1936) showed the presence of the beet curly top virus in all seed tissues except the embryo was confirmed through double antibody sandwich enzyme-linked immunosorbent assay (DAS-ELISA) and immunosorbent electron microscopy (ISEM). In the genus Begomovirus, the species abutilon mosaic virus was reported to be seed borne by Keur (1934). which has been disproved by Costa (1955). It has been hypothesized from these findings that the yellow mosaic virus can be transferred through seeds or insect vectors. Validation of transmission modes MYMV is carried out under this investigation.

\section{Materials and Methods}

\section{Mechanical transmission}

The phosphate buffer of $0.01 \mathrm{M}$ used for the mechanical transmission of the mungbean yellow mosaic virus. The mungbean seedlings raised in small plastic pots containing mixture of soil, sand and compost in 2:1:2 ratios (w/w) and 8-10 days' seedlings were used for the inoculation studies. Standard inoculum of the virus was prepared by collecting the leaf sample from seedlings showing typical yellow mosaic symptoms were maintained in glasshouse condition. The extract was prepared by macerating the infected plant material in $0.01 \mathrm{M}$ phosphate buffer ( $\mathrm{pH} 7.0$ ) in a 1:1 ratio using sterilized, pre chilled mortar and pestle. Crude extract was obtained by straining the ground tissues in nylon cloth. The plants were the inoculated by conventional leaf rub method given by Holmes (1920) with a pinch of 1per cent celite and drop of mercaptaethanol were added to inoculum $(0.025 \mathrm{~g} / \mathrm{ml})$ to serve as abrasive and inactivates the virus inhibitors, respectively. Then inoculated plants were labelled and kept in insect-proof screen cages and observed for symptom development up to two months.

\section{Transmission MYMV through different insect vectors}

\section{Rearing of whitefly (B. tabaci) culture}

Non viruliferous whiteflies were maintained on healthy cotton and brinjal leaves under glasshouse conditions. Initially few whiteflies were released in in the cage and they were allowed to lay eggs. Later, these virus free whiteflies were used for further transmission studies.

\section{Rearing of aphids (Aphis craccivora)}

For aphid transmission studies non viruliferous aphid (Aphis craccivora) colonies were maintained on cowpea plants in small insect proof cage.

\section{Rearing of mites (Tetranychus spp.)}

Twenty mulberry leaf bits of size $2 \mathrm{~cm}$ x $2 \mathrm{~cm}$ size were placed on wet cotton in plastic tray. Then adult red spider mites were released on 
each leaf bits to achieve the sufficient number of mites for MYMV transmission study.

\section{Transmission of MYMV through whiteflies}

Non-viruliferous whiteflies were used for the experimental transmission of the virus in controlled condition. Ten non-viruliferous whiteflies were collected with the help of the aspirator and released on the symptomatic leaves of mungbean covered with the cello plastic bottle. Whiteflies were allowed to feed on infected plant for 24 hours for the acquisition of the virus. On the next day, the whiteflies were removed and released on the newly emerged 10 days old healthy mungbean seedling in plastics bag filled with soil: FYM (3: I) mixture. The seedling was covered with the small cage to prevent escape of the whiteflies. Whiteflies were allowed to feed on the seedling for 24 hours and then were killed with systemic insecticides. Then inoculated plants were kept in insect proof cage for the symptom expression.

\section{Transmission of MYMV through Aphids}

Aphids were collected from rearing cage to petridish and starved for an hour by placing in a dark chamber before feeding on infected leaves for acquisition of virus. After the required acquisition feeding period, aphids were transferred to each of the test plant at the rate of 10 aphids/plants using a fine camel hairbrush and were given an inoculation feeding period of $24 \mathrm{hrs}$. At the end of required feeding period, plants were sprayed with 0.2 per cent Dimethoate to kill the aphids. The plants were labeled and kept under observation for the development of symptoms.

\section{Transmission of MYMV through mites}

Mites were collected from rearing cage to petriplate and starved for an hour by placing in a dark chamber before feeding on infected leaves for acquisition of virus. The starved mites in petridish were transferred on to infected leaves showing distinct mosaic symptoms. The mites were allowed for acquisition feeding time of $20 \mathrm{~min}$. At the end of acquisition feeding period, mites were transferred to each of the test plant at the rate of 10 mites/plants using a fine camel hairbrush and were given an inoculation feeding period of $24 \mathrm{hrs}$. At the end of required feeding period, plants were sprayed with 0.2 per cent dicofol (Acaricide) to kill the mites. The plants were labeled and kept under observation for the development of symptoms.

\section{Transmission of MYMV through seeds}

The mungbean seeds were collected from the MYMV infected plants and were sown in the polythene covers containing 1:2:1 ratio of sand, red soil and FYM were placed under the nylon net created in the field condition. These plants were watered carefully. In addition, seeds collected from the healthy plants were also sown in this plastic cover and placed in net house for symptom expression. After 5, 10 and 15 days of sowing, seedlings of mungbean were collected and subjected for molecular detection of MYMV through PCR method.

\section{Molecular detection of MYMV in whiteflies through PCR}

The total genomic DNA was extracted from viruliferous whiteflies based on modified CTAB method. The 200-250 whiteflies were collected and grounded with liquid nitrogen using sterile pestle and mortar. The whole grounded sample was transferred into a fresh 1.5-ml Eppendorf tube along with $500 \mu 1$ chilled TE, 70 $\mu 15 \%$ SDS and $6 \mu 1$ Proteinase$\mathrm{K}$ was added and mixed thoroughly. Then samples were incubated for $30 \mathrm{~min}$ at $55^{\circ} \mathrm{C}$ in a water bath with occasional mixing. Then supernatant was transferred into a fresh $1.5-\mathrm{ml}$ Effendorf tube and mixed with equal amountof Phenol: chloroform: isoamyl alcohol 
(25: $24: 1)$ by vertexing. The mixture was then centrifuged for about $10 \mathrm{~min}$ at $10,000 \mathrm{rpm}$. and supernatant obtained was transferred to a fresh tube. All the DNA extracts were further diluted from 1:10 to 1:40 in single distilled water (SDW) before using for PCR amplifications. The quality and quantity of DNA was assessed at $260 \mathrm{~nm}$ and $280 \mathrm{~nm}$ using Nano drop method.

\section{Primers used, PCR amplification and gel electrophoresis}

In order to determine the presence of mungbean yellow mosaic virus, specific primer was used to amplify coat protein region of yellow mosaic viruses of nearly $900 \mathrm{bp}$ Primers specific to MYMV(MYMV CP-F5'ATGGGKTCCGTTGTATGCTTG 3'\% MYMV CP-R-5'GGCGTCATTAGCATA GGCAAT 3') were used for amplification of coat protein gene of mungbean yellow mosaic virus (MYMV). PCR was performed in Thermocycler (Eppendorf Master cycler gradient) programmed for one step of initial denaturation at $94^{\circ}$ for $4 \mathrm{~min}$ and 35 cycles of denaturation at $94^{\circ} \mathrm{C}$ for $1 \mathrm{~min}$, annealing at $57^{\circ} \mathrm{C}$ for $1 \mathrm{~min}$ for primers MYMV-CPF/MYMV-CP-R and extension at $72^{\circ} \mathrm{C}$ for $1.30 \mathrm{~min}$, followed by one step of final extension at $72^{\circ} \mathrm{C}$ for $10 \mathrm{~min}$. PCR was conducted with Emerald Amp GT PCR Master mix in total reaction mixture volume of $25 \mu \mathrm{l}$ that contained Master mix- $12.50 \mu \mathrm{l}$; dH2O$6.50 \mu \mathrm{l}$; forward and reverse primers (20 pmole/ $\mu \mathrm{l}$ )- $2 \mu \mathrm{l}$ each; DNA template (total nucleic acid-100ng/ $\mu \mathrm{l})-2 \mu \mathrm{l}$, and PCR products were subjected to electrophoresis in $1.5 \%$ agarose at $50-70 \mathrm{~V}$ for 45 minutes in Electrophoresis system in Tris-acetate- EDTA buffer containing ethidium bromide @ $0.1 \%$. The gel was observed under Gel Documentation System (BIO-RAD).The protocol used for whiteflies DNA extraction was also used for the extraction of DNA from mites, aphids used and subjected for PCR amplification using MYMV CP primer and
PCR product was analyzed through agarose gel electrophoresis.

\section{Results and Discussion}

\section{Mechanical transmission}

Mechanical transmission of virus causing yellow mosaic virus disease was carried out on mungbean genotypes. The mechanical transmission results revealed that none of the genotypes produced symptoms of MYMV even up to 30 days after inoculation (Plate 1a) and presence or absence of virus was determined through PCR method. The electrophoresis of PCR products was $1.5 \%$ agarose.

The gel was observed in the gel documentation system and the results confirmed that there was no amplification of virus DNA (Table 1 and Plate $1 \mathrm{~b}$ ). The results revealed that the MYMV was not transmitted by sap inoculation method. Present results were in accordance with observation of Nariani (1960), who reported that transmission of the virus by sap inoculation by rubbing freshly extracted sap of mosaic affected leaves on healthy young seedlings of mungbean however, the MYMV disease could not be transmitted by sap inoculation method.

\section{Transmission of MYMV through whiteflies}

Plants started to show typical symptoms of MYMV within 7 days after the inoculation. Within 15 days, all the inoculated plants showed typical symptoms of the MYMV disease (Plate 2a).

PCR method used for the detection of virus in viruliferous whiteflies by using $\mathrm{CP}$ specific primers and A band of approximately 900 bp was amplified from total DNA extracted from viruliferous whiteflies while amplification was absent in non- viruliferous whiteflies (Table 1 and Plate 2b). The DNA amplification were 
obtained only in case of viruliferous whiteflies and there no bands obtained in non viruliferous. Similar results were also reported by Nair and Wilson (1969) who reported that MYMV was principally transmitted through the vector (B. tabaci) and that virus required acquisition and inoculation feeding period of $15 \mathrm{~min}$.

\section{Transmission of MYMV through Aphid}

None of the plants produced symptoms of MYMV even up to 30 days after inoculation (Plate 3a) and results of molecular detection of MYMV in aphids were also confirmed that amplification of virus DNA was absent in case of aphids (Table 1 and Plate $3 b$ ).

Thus these results confirmed that MYMV is not transmitted through aphids. These findings are in conformity with Dhingra (1975) where they reported that Aphis craccivora was unable to transmit MYMV in mungbean and other pulse crops.

\section{Transmission of MYMV through mites}

None of the plant produced symptom even up to 30 days after inoculation (Plate 4a) and results of molecular detection of MYMV in mites were also confirmed that amplification of virus DNA was absent in case of aphids (Table 1 and Plate 4b). Thus these results confirmed that MYMV is not transmitted through mites. The present findings were in confirmation with the results reported by Muniyappa and Nangia (1982) and Rajnimala et al., (2005) where they have reported that Red spider mite and other species were not responsible for the transmission.

\section{Transmission of MYMV through seed}

None of the plants developed the symptoms of MYMV even up to 35 days after sowing
(Table 3 and Plate 5a) and also results of molecular detection of MYMV through PCR confirmed that there was no amplification of virus DNA (Table 1 Plate 5b). These results indicating that virus is not transmitted through seeds. The present investigation results were similar to that of the findings of Nariani (1960) wherein MYMV was not seed transmittable. Similar report was also given by Ahmed and Harwood (1973), Nair and Nene (1973) and Gautam (1990). Nair and Wilson (1969) found that mungbean yellow mosaic virus was not transmitted through the seed. MYMV was not seed born in nature due to this restricted distribution and also it was inferred that in general geminivirus, specifically begomoviruses cannot enter into seed parts as the vascular supply to the seed is partially only up to the hilum region of the seed coat (Hull 2002).

In this present investigation mungbean yellow mosaic virus disease transmission studies were carried out by three different methods viz., Sap inoculation, insect and seed transmission. Among the different modes of virus transmission, whitefly transmission of viruses is of important as the viruses may persist in the vector for a period and may spread the diseases into other plant.

In the present study confirmed that MYMV was not transmitted by mechanical sap inoculation, mite and aphid in mungbean plants. While, viruliferous whitefly transmitted MYMV up to 80 per cent in mungbean plants.

The one of the most important aspect of the present investigation is the detection of MYMV in seeds is whether they will serve as a potential inoculum of the virus source or not. In which case, it will be of great concern in plant quarantine and trade-related movement of the seeds. 
Table.1 Studies on transmission of Mungbean Yellow Mosaic Virus (MYMV) through different methods

\begin{tabular}{|c|c|c|c|c|c|c|}
\hline \multirow[t]{2}{*}{ Sl.no } & \multirow{2}{*}{$\begin{array}{l}\text { Method of } \\
\text { transmission }\end{array}$} & \multicolumn{2}{|c|}{ Number of plants } & \multirow{2}{*}{$\begin{array}{l}\text { Types of } \\
\text { symptom }\end{array}$} & \multirow{2}{*}{$\begin{array}{c}\text { Percent } \\
\text { transmission }\end{array}$} & \multirow{2}{*}{$\begin{array}{l}\text { PCR } \\
\text { results }\end{array}$} \\
\hline & & inoculated & infected & & & \\
\hline 1 & Mechanical & 20 & 0 & - & 0 & - \\
\hline 2 & Whiteflies & 20 & 17 & $\begin{array}{c}\text { Severe yellow, } \\
\text { discoloration } \\
\text { stunting of plants }\end{array}$ & 85 & - \\
\hline 3 & Aphids & 20 & 0 & - & 0 & - \\
\hline 4 & Mites & 20 & 0 & - & 0 & - \\
\hline 5 & Seeds & 20 & 0 & - & 0 & - \\
\hline
\end{tabular}

Plate.1a) Sap inoculated plant without MYMV symptoms. b) Detection of MYMV in the sap inoculated mungbean plant species using MYMV Coat Protein specific primer M: 100bp Ladder Lane 1: Infected mungbean leaf sample (Positive control) Lane 2\& 3: Leaf sample collected sap inoculated mungbean plants
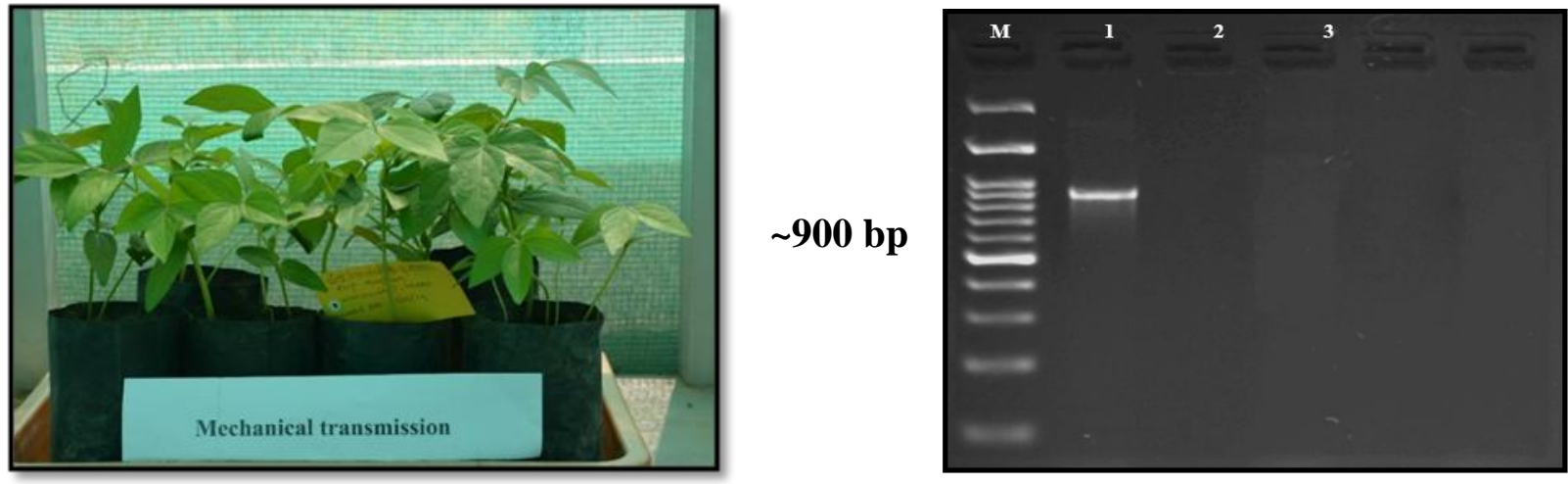

Plate.2a A. MYMV infected plant (Positive control). B. Whitflies inoculated mungbean plant with symptoms. 2b. PCR amplification of MYMV in the viruliferous whitefly by using MYMV Coat Protein specific primer. M: 100bp Ladder, Lane 1: Infected mungbean leaf sample (Positive control), Lane 3 \& 5: Viruliferous whitefly sample, Lane 2 \& 4: Aviruliferous whitefly sample
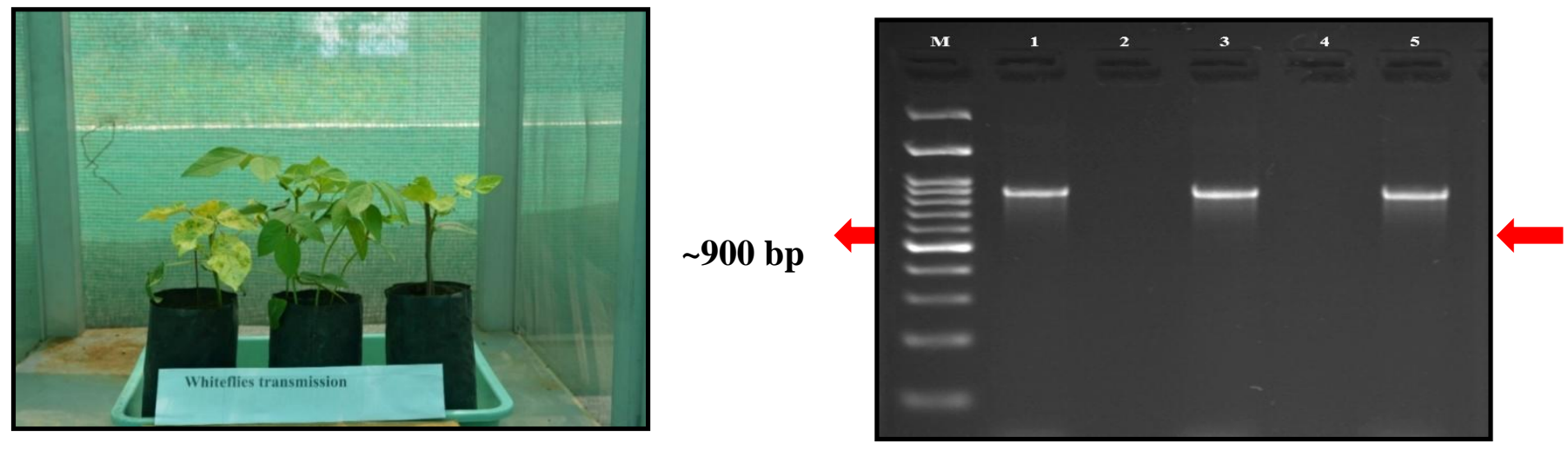
Plate.3a A. MYMV infected plant (Positive control); B. Aphids inoculated mungbean plant without symptoms; 3b. Detection of MYMV in the viruliferous Aphid by using MYMV Coat Protein specific primer. M: 100bp Ladder, Lane 1: Infected mungbean leaf sample (Positive control), Lane $2 \& 4$ : Aviruliferous aphid sample, Lane $3 \&$ 5: Viruliferous aphid sample
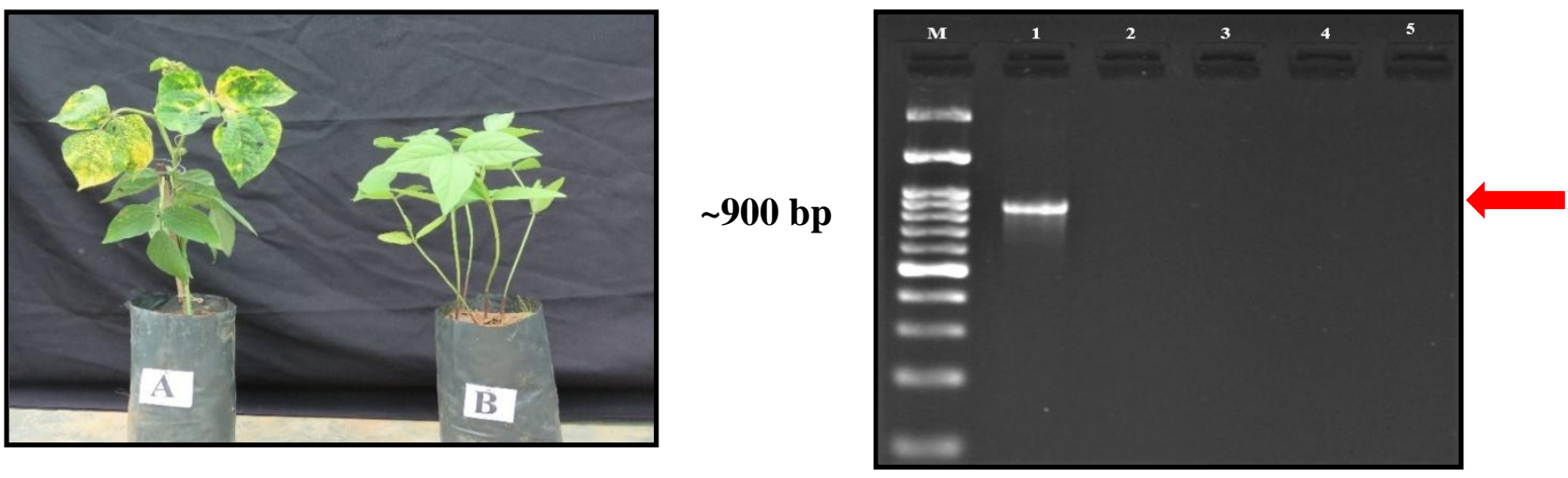

Plate.4a) A. MYMV infected plant (Positive control), B. Mites inoculated mungbean plant without any symptoms. b) M: 100bp Ladder, Lane 1: Infected mungbean leaf sample (Positive control), Lane 3 \& 5: Viruliferous mite sample, Lane 2 \& 4: Aviruliferous mite sample
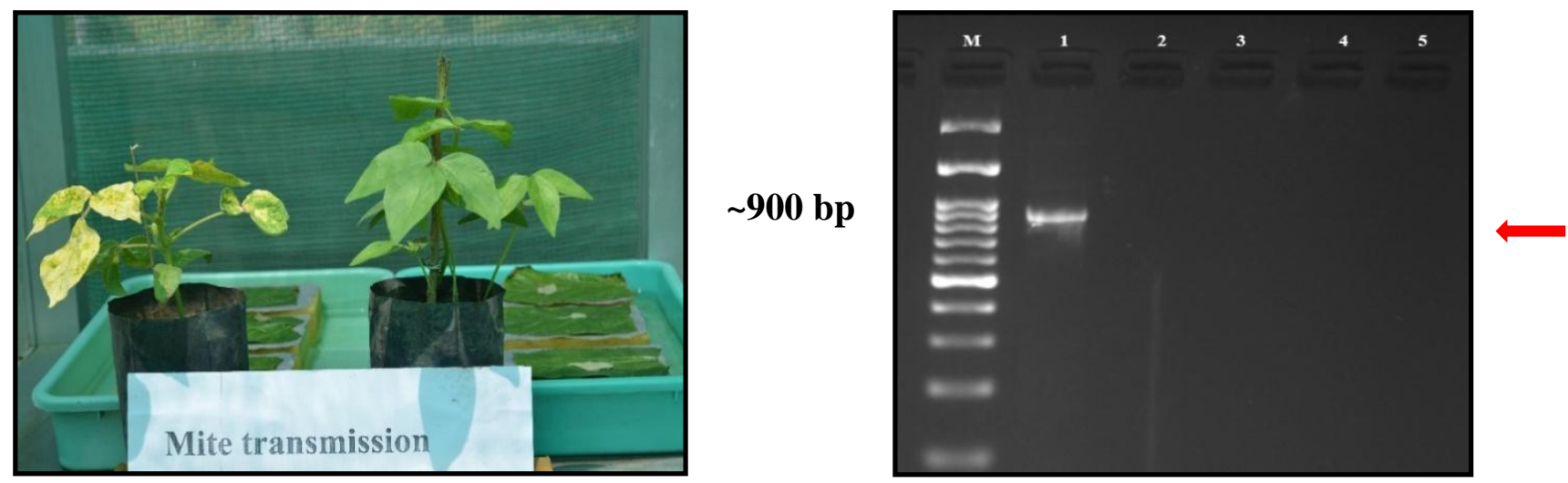

Plate.5a Transmission studies of MYMV through seeds; b)Detection of MYMV in the mungbean yellow mosaic infected seed by using MYMV specific coat protein specific primer. M: 100bp Ladder, Lane 1: Infected mungbean leaf sample (Positive control), Lane 2: MYMV infected seed (Dry seed), Lane 3: Seedlings of 5 days after germination, Lane 4: Seedlings of 10 days after germination, Lane 5: Seedlings of 15 days after germination

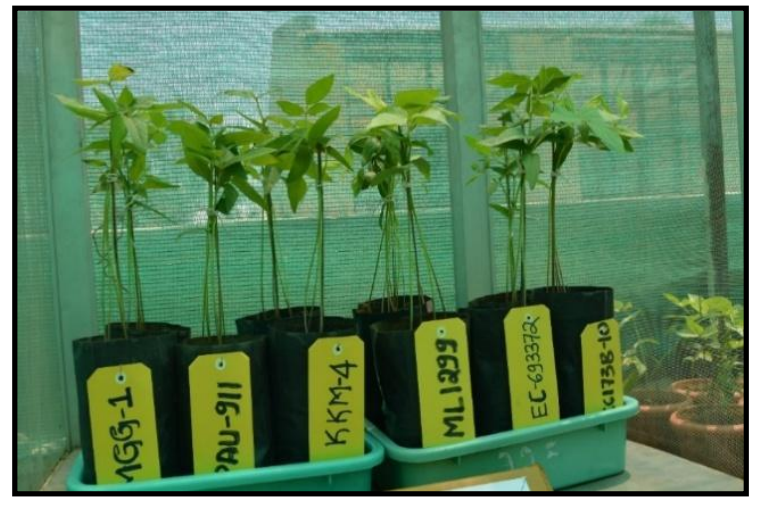

$\sim 900$ bp

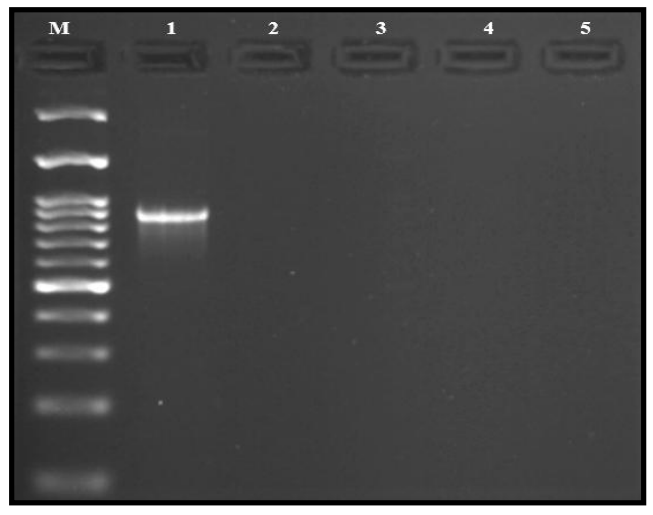


Whether the presence of virus in seeds will contribute as initial inocuium within the field, which then gets actively transmitted within the field, is a key question which should be addressed immediately. Future work should focus on the mechanism of the movement of the virus in whiteflies in detail and different genotypes of mungbean and different legume hosts.

\section{References}

Ahmad, M. and Hardwood, R. F.(1973). Studies on a whitefly-transmitted yellow mosaic of urdbean (Phaseolus mungo). Plant Dis. Rep., 57(9): 800802.

Bennett C, W. (1936). Further studies on the relation of the curly top virus to plant tissues. J. Agric., Res53:595-620

Chatterjee, D. and Randhawa, G. S. (1952). Standardized names of cultivated plants in India. II. Cereals, pulses, vegetables, and spices. Indian J. Hort., 9:64-84.

Costa A S. (1955). Studies of Abutilon mosaic in Brazil. Phytopathol, 24:97-112

Dhingra, K. L. and Ghosh, D. K. (1975) Efficiency of whitefly vector (Bemisia tabaci Genn.) in transmission of mungbean yellow mosaic virus in different source test plant combinations. Int. J. Trop. Agric., 11: 149-152.

Gautam, H. C. (1990). Identification of soybean diseases and their integrated control. Curr. Trop. Pathol., 15-22.
Holmes, F. O. (1929). Local lesion into bacco mosaic Bot. Gaz.39: 55.

Hull R., (2002) Matthews's plant virology. Academic, New York

Keur J.Y. (1934). Studies of the occurrence of and transmission of virus diseases in the genus Abutilon. Bull Torrey Bot Club 61:53-70

Muniyappa, U. and Nangia, N.(1982). Pigeon pea cultivars and selection for resistance to sterility mosaic in relation to the prevalence of the eriophyid mite Acerja cajani. Trop. Grain Legume Bull. No., 25:28-30.

Nair, N. G. and Nene, Y. L. (1973). Studies on the yellow mosaic of urdbean caused by mungbean yellow mosaic virus II. virus-vector relationships. Indian $J$. Farm Sci. 1: 62-70.

Nair, R. R. and Wilson, K, I. (1969). Studies on some whiteflies transmitted plant viruses from Kerala. Agric. Res. J. Kerala., 7: 123-126.

Nariani, T. K. (1960). Yellow mosaic of mung (Phaseolus aureus). Indian Phytopathol.media., 14: 55-59.

Rajnimala, N., Rabindran, R., Ramiah, M. And Kamlalkhan, A.(2005). Virus vector relationship of bitter gourd yellow mosaic virus and whitefly, Bemisiatabaci. Phytopath. Entomol. Hung., 40:23-30.

Rojas MR, Hagen C, Lucas W.J, Gilbertson R. L. (2005). Exploiting chinks in the plant's armor: evolution and emergence of geminiviruses. Annu Rev Phytopathol., 43:361-394

\section{How to cite this article:}

Mantesh, M., Venkatesh and Pankaja, N.S. 2019. Validation of the Modes of Transmission of Mungbean Yellow Mosaic Virus (MYMV) in Mungbean [Vigna radiata (L.) Wilczek]. Int.J.Curr.Microbiol.App.Sci. 8(11): 950-957. doi: https://doi.org/10.20546/ijcmas.2019.811.111 